\title{
SIMPLIFYING PHOTOGRAMMETRIC ANALYSIS FOR ASSESSMENT OF LARGE MAMMAL MASS: AUTOMATED TARGETING AND 3D MODEL BUILDING
}

\author{
L. CATHERINE BESTER (lcbester@zoology.up.ac.za) \\ P. J. NICO DE BRUYN (pjndebruyn@zoology.up.ac.za) \\ Mammal Research Institute, Department of Zoology \& Entomology, University of \\ Pretoria, South Africa
}

\begin{abstract}
Close range photogrammetry has increasingly diverse practical application within the biological sciences. Its use in large mammal research for size and/or mass estimation has proven extremely beneficial. Recent photogrammetric technique advancements have improved its applicability in the field, although some analytical components remain time consuming. The use of automated coded targets, associated with commercially available software, was evaluated to simplify photogrammetric analysis without compromising its practicality. The effects of variable target size and shape, lighting conditions, number of photographs, photograph target coverage and project processing time were assessed. Augmenting a published photogrammetric field technique by including coded targets greatly reduced analysis time. The simplified method is attractive for use by a wider range of both specialist and non-specialist users for applications within the animal photogrammetry field.
\end{abstract}

KEYWORDS: zoological application, mammal photogrammetry, low-cost software, automated coded targets, mass estimation

\section{INTRODUCTION}

DIGITAL PHOTOGRAMMETRY AND THREE-DIMENSIONAL (3D) LASER SCANNING have proven useful in the biological sciences. Close range photogrammetry is a useful technology in more dynamic settings and may be applicable in a range of applications (Luhmann et al., 2010). Where laboratory conditions cannot be met, or where collection of measurement data is necessary in field settings (where minimal equipment requirements are preferable), close range photogrammetry has gained significant ground.

The use of close range photogrammetry in animal research is relatively recent, but of increasing interest. Several advancements have contributed to its use and its application to various species in different scenarios. For the purposes of this paper only mammals are 
considered, given that a range of mammalian species in different environments has been exposed to photogrammetric assessments, thereby providing a useful overview group with applicability beyond an individual class. Scaling relationships exist between the morphological measures and the body mass or size of mammals; thus diverse morphological measures can be ascertained using assorted photogrammetric techniques (such as Ratnaswamy and Winn, 1993; Bergeron, 2007; Rothman et al., 2008; and Berger, 2012). Many scaling relationships are, however, species specific, thus requiring renewed validation of photogrammetric approaches for each species. Such validation can be costly and time consuming when the morphological measures or mass estimates are often just covariates of more general ecological/biological questions and not the ultimate purpose of the mammal research itself. Nonetheless, species-specific advances have been made explicitly where estimates of body mass are concerned. Much research on mass estimation using morphological attributes has been done on pinnipeds (seals) (Haley et al., 1991; Bell et al., 1997). This can be attributed to their hydrodynamic body shape and the fact that much of their limbs are contained within the general surface of the body. Accurate mass and body-size estimation in large mammals are important factors that play a crucial role in studies of, amongst others, physiology (Swihart et al., 1988), life history (Western, 1979) and metabolic activities (Darveau et al., 2002).

The use of three-dimensional (3D) close range photogrammetry greatly improves the estimation of body mass and morphometrics, as it reduces many of the difficulties associated with two-dimensional (2D) photogrammetry (Waite et al., 2007). Threedimensional photogrammetry has also provided the first significant move towards assessments of mammal mass that are not species specific by using the space around the animal for orientation and scaling, rather than the animal itself (de Bruyn et al., 2009).

Traditional methods for obtaining body-size and mass data tend to constrain the researcher's ability to collect a statistically significant number of samples (Ireland et al., 2006). They also make it difficult to sample effectively without causing distress to the animal as mass data collection, especially in the case of large mammals, often requires capture and restraint or immobilisation (van den Hoff et al., 2005; Ireland et al., 2006).

Photogrammetry provides a potential solution to some of these problems for mass estimation, specifically in pinnipeds. Estimating mass from photographs made it easier to sample far more efficiently across populations, with reduced disturbance to the animal (Ireland et al., 2006; Waite et al., 2007; Proffitt et al., 2008).

These photogrammetric methods were more effective and less labour intensive than traditional weighing, but remained constrained by various complexities for their use in the field. De Bruyn et al. (2009) provided a simpler photogrammetric method of mass estimation for a large mammal in the field which essentially required a single photographer equipped with a digital camera and a known scaling measure (such as a calibrated walking stick) to be placed in the photographed area . An aim of that study was to seek a less customised approach for large mammal photogrammetry, achieving this by:

(1) moving away from a species-specific approach (although the technique was tested for mass estimation of only one species, it is basically a volume estimation method applicable to any object, which is then converted to a mass estimate); and

(2) utilising commercially available camera and software products.

Although little time is required to take the photographs in the field, the subsequent analysis and accurate 3D-model creation takes a lot of time. This time-consuming and 
often daunting analytical component tends to be a factor which limits the use of photogrammetry (Fussell, 1982). One improvement to the accuracy and temporal efficiency of photogrammetry is the incorporation of artificial targets into the digital images (van den Heuvel et al., 1992; Ahn et al., 2001). Coded targets are considered as one of the major innovations facilitating fully automated photogrammetric measurement (Fraser, 1997). Utilisation of coded targets in industrial measurement (Shortis and Seager, 2014) has also advanced the precision of measurements from images. The fine-tuned accuracy and dramatically reduced processing time demonstrated through the use of coded targets by Hattori et al. (2002) is one such example. More than one type of coded target exists, including concentric rings (van den Heuvel et al., 1992; Schneider and Sinnreich, 1992), squares (Shortis and Seager, 2014) and dot distributions (Ganci and Handley, 1998; Pappa et al., 2003). Coded targets of any form have, however, not been used in zoological applications under natural field conditions and their implementation requires initial testing.

The 'automated coded targeting' application within Photomodeler Scanner ${ }^{\circledR}$ (EOS Systems Inc., Canada) is one product that has the potential to greatly reduce the analytical time required for photogrammetric analysis. This software and associated coded targets have been introduced into the existing 'de Bruyn' photogrammetric method (de Bruyn et al., 2009) of volume (mass) estimation. This paper examines the addition of automated coded targets to the existing de Bruyn et al. (2009) photogrammetric field methodology in order to ease the analytical process of photograph orientation and 3D model construction, without compromising the user-friendly field methodology. Importantly, this paper is not aimed at assessing the accuracy of actual volume/mass estimation (given that this was the scope of the original 2009 paper), but rather whether incorporation of automated components can alleviate the time-consuming nature of the analytical procedure in that method.

\section{METHOD AND MATERIALS}

This section outlines the various attributes and characteristics of the approach adopted in this paper.

\section{Study Species}

Various large African mammals, namely African elephants (Loxodonta africana), white rhinoceroses (Ceratotherium simum) and hippopotamuses (Hippopotamus amphibious) were photographed while under anaesthesia. The elephants were from Selati Game Reserve in Limpopo province, South Africa; the rhinoceroses were from both Kruger National Park and Mauricedale Game Reserve in Mpumalanga province, South Africa; and the hippopotamuses were also from Kruger National Park. Photographs were taken according to the existing de Bruyn et al. (2009) photogrammetric method with the addition of multiple coded targets (see below). As well as the live subjects, several inanimate objects were photographed in order to perfect the augmented photogrammetric field procedure. The inanimate objects used were plastic containers of known volume. 


\section{Study Area}

Photogrammetric data for elephants, rhinoceroses and hippopotamuses were collected either in the Kruger National Park, Selati Game Reserve or Mauricedale Game Ranch in the Lowveld of Mpumulanga Province, South Africa. The photogrammetric experimental trials using inanimate objects were conducted in a suitable open area in residential Pretoria, Gauteng Province, South Africa.

\section{Photographic Procedure}

The large mammals (of varying age and sex) were photographed using a Canon EOS 450D single-lens-reflex digital camera with an $18-55 \mathrm{~mm}$ Ultrasonic Canon lens set (by means of adhesive tape) to the minimum $18 \mathrm{~mm}$ focal length setting, that had been calibrated according to the procedure outlined by the Photomodeler Pro ${ }^{\circledR}$, Version 6.2 software, November 2010 (EOS Systems Inc. Vancouver, Canada). In independent comparisons between several software packages and traditional calibration procedures, Photomodeler ${ }^{\circledR}$ calibration procedures were shown to be accurate and repeatable for close range photogrammetry applications (Remondino and Fraser 2006). The actual mass of these mammals was known. The de Bruyn et al. (2009) photographic procedure was used in the field and should be referred to for details. In summary, eight to ten photographs are taken of the subject from various heights and angles stationed around the subject (this translates to one 'project'). Due to a scaling measure of known length (a calibrated measuring stick) being visible in at least three of the photographs that comprise a project, and given the use of a fully calibrated camera, these camera stations need not be at exactly the same sites for the scaling and orientation to be successfully accomplished. This method utilised random natural or inserted substrate markers for manual identification by the user during analysis for $3 \mathrm{D}$ orientation of the photographs. The purpose was to assess whether the addition of coded targets (automatically identifiable by the Photomodeler ${ }^{\circledR}$ software) would alleviate the time-consuming manual analysis.

Coded targets were therefore introduced into the photogrammetric field projects measuring large wild mammals. However, to test in what form these targets needed to appear within the set-up, photographs of various inanimate objects were taken in order to provide baseline data. To test the efficiency of the automated coded targets, three types of projects were compared: (i) using the existing manual method only; (ii) using the coded targets only; and (iii) using a combination of the manual method and the coded targets.

\section{Automated Coded Targets}

The Photomodeler ${ }^{\circledR}$ software provides 999 unique coded targets. The sizes of targets can be adjusted to suit individual project needs. These targets are high contrast circles which allow for accurate sub-pixel point marking. The software is programmed to recognise each target and pinpoint (to sub-pixel accuracy), the midpoint of each. The target sizes are given as the diameter of the centre circle of the target, which can be adjusted. This project made use of ringed automatically detected (RAD) targets. For the purposes of compatibility with the established de Bruyn et al. (2009) method, it was 
necessary to assess the following aspects:

(1) Lighting Conditions. Determining the effect of ambient light on the software's ability to identify individual targets and orientate photographs. Coded-target arrangements in field scenarios, as described in de Bruyn et al. (2009), were evaluated in conditions of full sunlight, dappled shade and full shade.

(2) Number of Targets. When photographing large mammals it was estimated that between 40 and 70 coded targets are required, depending on the field scenario and size of the subject. This would have to be quantified using the de Bruyn et al. (2009) method augmented with numerous coded targets.

(3) Target Size. Determining the most effective target size for the specific objectives of this study. The software allows for customisation of target size (see above). The research evaluated the software's ability to identify and process targets of varying sizes in a field scenario typical of the implementation of the de Bruyn et al. (2009) method, but without measuring the subject. This was merely to test the identification and photographic orientation of the targets themselves. Camera stations were positioned around the subject at a distance which allowed for the entire object, as well as sufficient substrate (upon which coded targets were placed), to be captured in the picture frame. In other words, the required distance away from a large mammal, such as an elephant, in order to fit the entire animal in the frame, would presumably require the positioning of larger targets around the animal to ensure the software can actually "see" them when the photographs are processed. A target size was considered effective when the program was able to identify at least $60 \%$ of the coded targets and able to successfully orientate all photographs. The coded targets were printed out in black onto sheets of white A4 paper, each sheet containing targets of a different size. Coded targets with inner diameters of $3,5,8,10,12$, 16 and $25 \mathrm{~mm}$ were all tested individually in the manner mentioned above, and then several sheets of differing coded target sizes were tested together, to ascertain whether the program could process a project with different sized targets.

(4) Target Shape. Once an ideal target size was determined, the targets were mounted on various objects of differing size and shape to determine whether this would have an effect on the efficiency of identification of the automated coded targets. The shapes evaluated in this experiment included standard tennis balls (approximately $67 \mathrm{~mm}$ in diameter); three-dimensional cubes $(65 \times 65 \times 65 \mathrm{~mm})$; small cones (lower diameter of $190 \mathrm{~mm}$ and an upper diameter of $60 \mathrm{~mm}$ ); and flat, laminated A4 cardboard sheets.

(5) Photograph Target Coverage. The required photographic coverage needed for successful processing by these targets was tested. Pixel-level grid cell evaluations were done using randomly selected photographs from both successful and unsuccessful coded target projects. The photographs $(2848 \times 2134$ pixels $)$ were subdivided into 176 quadrants, each measuring $178 \times 194$ pixels (34 532 pixels per quadrant). The mean number of pixels occupied by the coded targets per quadrant was calculated. The actual size of the targets (in pixels) in a given photograph, taken at a distance required to include both the entire subject and targets in the frame, was also quantified. 
(6) Number of Photographs. According to the de Bruyn et al. (2009) method, an individual photogrammetric project requires between 8 and 10 photographs. In this context, a 'project' was defined as the process of orientating the photographs, taken of a specific subject, by the software. The optimal number of photographs was determined by evaluating the outcome of several projects, each with an increasing number of photographs. The success of a project utilising a certain number of photographs was evaluated using the overall root mean square (RMS) precision values (in pixels), a value provided by the software. The marking residual indicates a residual error for each point on the photograph (the difference between where one places the mark and where the program expects the mark to be). Marking residuals are considered to be the best indicator of project quality. A weak overall RMS mark residual value means that the RMS of the largest marking residual from all points in a project has exceeded the program threshold and therefore a large overall RMS value suggests the project is not providing an adequate solution. A successful project is considered to be one with an overall RMS value of less than 5.00 pixels (see de Bruyn et al., 2009). This research tested how many photographs were required before an asymptote was reached, and thus where any additional photographs did not significantly improve the volumetric estimate of the subject. The first test utilised four photographs of a chosen subject taken perpendicularly in relation to the object. The second project utilised four photographs taken diagonally in relation to the chosen object. The third project utilised six photographs evenly spaced around the object. The fourth project utilizsed 8 photographs, and so on. The success of the projects was evaluated by making use of up to 24 photographs.

(7) Orientation Time. The time taken to orientate photographs in the various projects using the de Bruyn et al. (2009) methodology were compared as a measure of ease and efficiency using: (i) the manual method only; (ii) the coded-target method only; and (iii) a combination of the manual and coded-target methods .

\section{Photogrammetric Analysis}

Photograph orientation is required for successful $3 \mathrm{D}$ modelling to be accomplished. This requires the following three processes:

(1) Unique marks are identified, either manually or automatically, depending on the type of project.

(2) The same corresponding marks are identified on different photographs (photographs from different camera angles) and cross-referenced.

(3) A sufficient number of cross-referenced marks on each photograph allow the photographs to be orientated relative to other photographs in 3D space.

The time taken for the automated recognition of the coded targets in photographs by the software was used as a measure of the efficiency of the coded targets. Photographs of elephants and hippopotamuses were subjected to manual orientation using the Photomodeler ${ }^{\circledR}$ software exactly as described for seals in de Bruyn et al. (2009), to act as an experimental control. The white rhinoceros photographs were oriented using a combination of both the automated coded targets and manual orientation. The inanimate object photographs and some of the white rhinoceros photographs were orientated using only the coded targets. 


\section{Data Analysis}

Various parameters associated with the manual and automated projects were compared for analysis. Accuracy and precision parameters in the photograph orientation, cross-referencing and 3D model-construction stages is reported during calculation by the software. Project processing potential is predicted based on the (cross-referenced) number, distribution and location of identified targets within the photographs. Of particular interest to the current application is the residual error (RMS) of each selected point in the photographs. The de Bruyn et al. (2009) method identified checks that involve the following criteria, amongst others:

(1) Project processing potential should score 3 or more out of 5, as assessed by the software, before the addition of further photographs beyond the initial four photographs.

(2) RMS for all points should not exceed 5 pixels at the time when outlines of animals are cross-referenced and measured (for additional details see de Bruyn et al. 2009).

The formation of a 3D model that accurately represents reality depends on compliance with all of these checks. Each project submitted to manual or automated manipulation will produce an orientated 3D space within which any object can be modelled, assuming all the de Bruyn et al. (2009) stipulated checks are satisfied. Data was tested for normality and homogeneity and analysed using Shapiro-Wilk tests, Kruskal-Wallis tests, MannWhitney $U$ tests and generalised estimating equations. Data was processed using STATISTICA Version 10.0 (Statsoft Inc. Tulsa, USA) and SPSS Version 19.0.0 (SPSS Inc. Chicago, USA).

\section{RESULTS}

Photographs of elephants and the hippopotamuses were oriented using the manual method only. The rhinoceros projects were orientated using coded targets only, with projects being both successful and unsuccessful for various reasons. The benefit herein was that reasons for the failures in processing could be sought with subsequent photographic trials on inanimate objects in order to further finetune the method. Identifying the impediments in the analytical process are just as valuable in addressing the objectives of the research as the features in the processes that succeed. These unsuccessful rhinoceros projects were then processed using a combination of both coded targets and manual manipulation for 3D orientation. The inanimate object photographic trials were successfully orientated using the automated coded target method only, as were a few successful rhino projects.

Given the existence of a successful manual approach to 3D model construction (de Bruyn et al., 2009), the prime interest here was to assess the software's abilities in recognising coded targets in the relevant environments automatically. Even if complete orientation was unsuccessful with the exclusive use of coded targets (manual marking is also required), the reduction in analytical time needed, as compared with fully manual marking, was of interest.

The same seven headings as in the subsection Automated Coded Targets above are used to assess the results. 
(1) Lighting Conditions. In general, lighting did not appear to be a major factor in the software's ability to recognise coded targets, with targets being effectively identified from photographs taken in both full sun and full shade. In certain instances, however, direct sun resulted in glare or reflection off the surface of the coded targets. Dappled shade proved to be a limiting factor only when testing small target sizes. In terms of photographs taken at night, the flash provides adequate light for smaller species, but with larger species the flash may fail to effectively illuminate the whole area (most likely only lighting up the foreground) and auxiliary lighting may be required.

(2) Number of Targets. The number of targets required for a successful project was greatly dependent on the size of the object in question. During the experimental trials, only 14 individual targets were used for a small object (such as a 10-litre bucket), with complete success in photograph orientation and model construction. A medium sized object (for example a 60-litre crate) was evaluated using approximately 40 targets with similarly good results. Between 30 and 40 targets were utilsed for the rhinoceros photographic trials. However, this number proved to be insufficient for such a large object (where the photo-frame included more area by necessity of the size of the object) as the software was unable to recognize a sufficient number of targets within the field of view of the photographs. Placement and adequate photographic coverage by coded targets appears to be a more relevant measure than the number of targets required (see below).

(3) Target Size. The program was equally capable of processing individual projects with coded targets of a single size or a single project with targets of various sizes. When only single-sized targets were used per project, the smaller sized targets ( $3 \mathrm{~mm}$ to $10 \mathrm{~mm})$ proved ineffective at the scale of a medium-to-large mammalian species. The program was unable to identify small targets from all camera stations/angles and was unable to orientate any of the photographs. The $12 \mathrm{~mm}$ targets were partially effective as the software was able to identify approximately $<65 \%$ of the targets but was only able to orientate certain photographs. The ideal target size proved to be those with diameters of $25 \mathrm{~mm}$; all targets were identified by the program and all photographs were easily orientated during the trials. See (5) below for additional details pertaining to the relative pixel size of targets.

(4) Target Shape. The spherical tennis ball proved to be completely ineffective as a surface to mount targets; the program was unable to identify any of the targets $(3 \mathrm{~mm})$ attached to the surface of the tennis ball. The cubes and cones were partially effective. Although approximately $50 \%$ of the targets were identified in any one photograph, the software was unable to identify a sufficient number of the same coded target in other photographs, thus resulting in few photographs being orientated. However, the combination of both cones and cubes provided better results. The majority of the coded targets were identified and almost all photographs were orientated. However, a flat sheet on which a single, large $(\leq 25 \mathrm{~mm})$ target was printed proved to be the most effective target design, resulting in over $90 \%$ of targets in a given project being recognised by the software and all the photographs being orientated.

(5) Photograph Target Coverage. The effective target coverage in the photographs appears to be more important than the actual number of targets used. The mean pixel 
target coverage per quadrant (34532 pixels) from photographs of all unsuccessful projects $(325 \cdot 35 \pm 117 \cdot 41$ pixels $)$ compared to the mean pixel target coverage per quadrant for all successful projects $(2040 \cdot 24 \pm 488 \cdot 29$ pixels) differed significantly (Mann-Whitney $\mathrm{U}$ test, $\mathrm{Z}=-3 \cdot 062, \mathrm{p}<0 \cdot 05$ ) (Fig. 1 ).

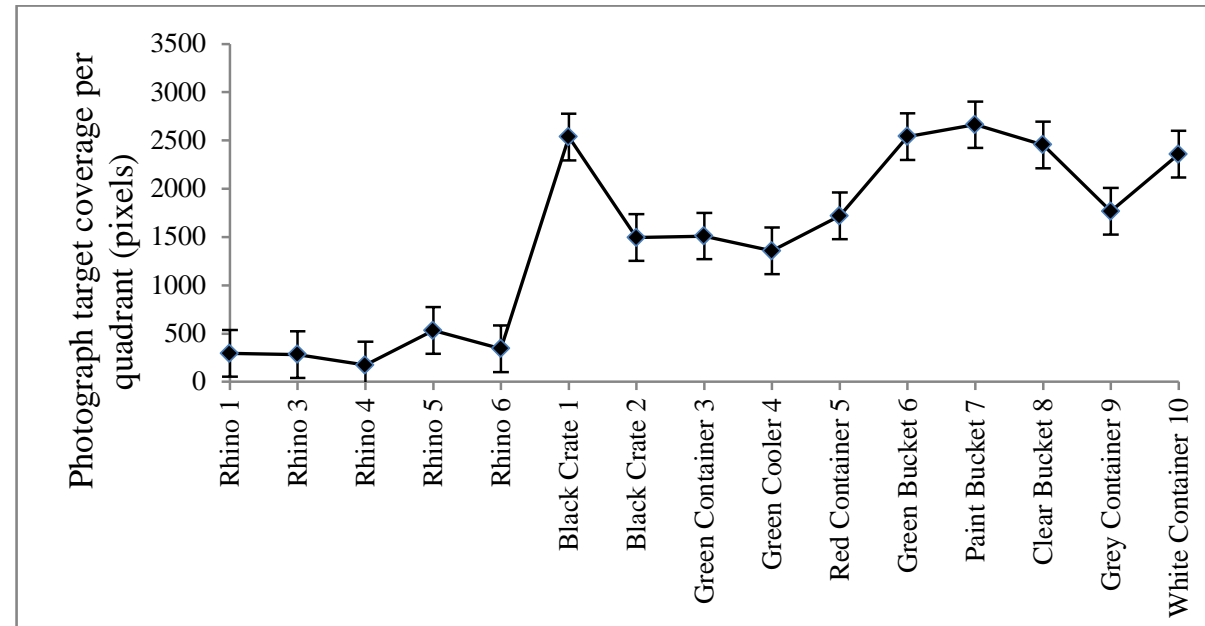

Object

FIG. 1. Mean total photograph target coverage per quadrant (pixels) per photograph for each individual project. The projects 'Rhino 1' through to 'Rhino 6' were unsuccessful.

The projects 'Black Crate 1' through to 'White Container 10' were successfully processed.

The mean target size (in pixels) from photographs of all unsuccessful projects $(3945 \cdot 6 \pm 2016)$ compared with the mean target size for all successful projects $(10480$ $\pm 2495 \cdot 8$ ) differed significantly (Mann-Whitney U test, $Z=-3 \cdot 062, \mathrm{p}<0 \cdot 05$ ) (Fig. 2). 


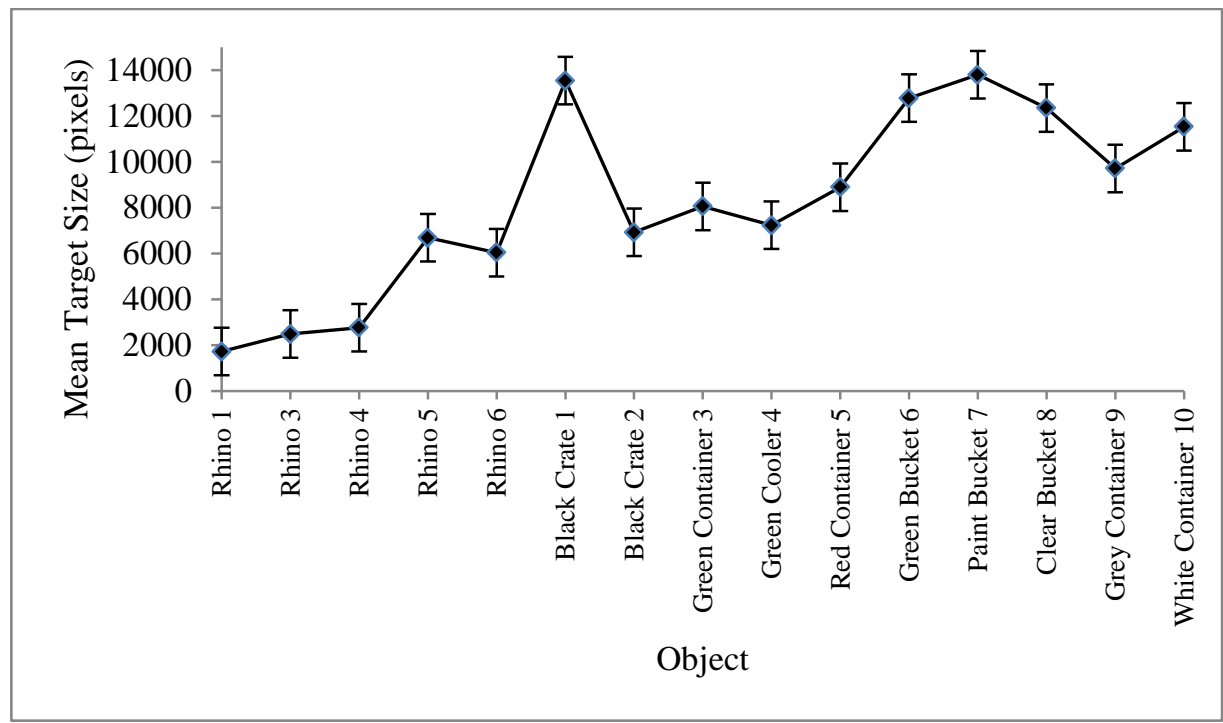

FIG. 2. Mean coded target size (pixels) for each individual project.

The projects 'Rhino 1' through to 'Rhino 6' were unsuccessful.

The projects 'Black Crate 1' through to 'White Container 10' were successfully processed.

In the unsuccessful projects, target sizes from the foreground of the photos (the largest targets) occupied approximately $8127 \cdot 3( \pm 4418.5)$ pixels. The targets on the opposite side of the object relative to the observer (the smallest targets) occupied approximately $1185 \cdot 3( \pm 875 \cdot 25)$ pixels . In the successful projects, target sizes from the foreground of the photos occupied approximately $24252 \cdot 03( \pm 7701 \cdot 11)$ pixels. The targets behind the object occupied approximately $3757 \cdot 27( \pm 952 \cdot 89)$ pixels.

Importantly, although this minimum target coverage is required per photograph to permit accurate identification of coded targets, the software requires the centre dot of the targets to be approximately 10 pixels or more in diameter for naturally lit targets.

(6) Number of photographs. The mean overall RMS values obtained for projects with differing numbers of photographs were all very similar and well below the $5 \cdot 0$ pixel RMS threshold recommended for a successful project by de Bruyn et al. (2009). Twelve photographs had the second lowest mean RMS value $(0 \cdot 3966 \pm 0 \cdot 0657$ pixels) (Fig. 3). 


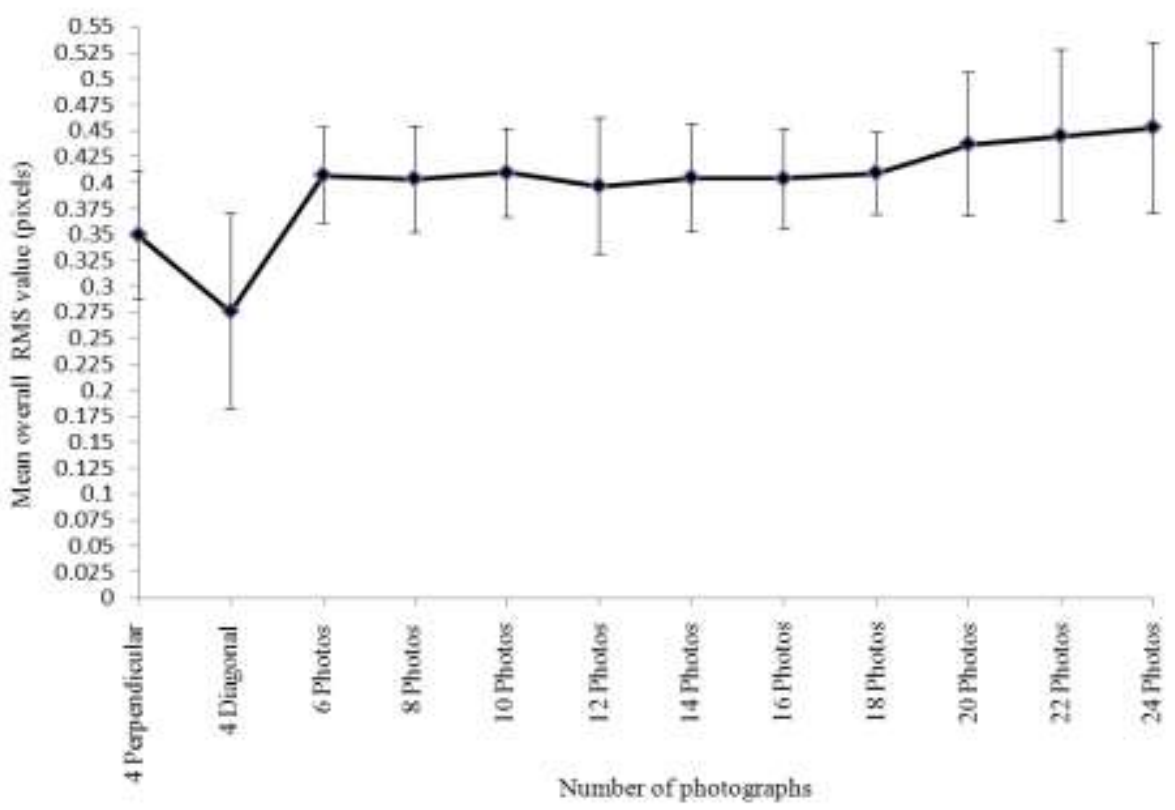

FIG. 3. Mean overall RMS values (pixels) for the increasing number of photographs used to complete a project.

The lowest mean RMS value was for projects using photographs specifically taken diagonally in relation to the object of interest $(0 \cdot 2754 \pm 0 \cdot 0943$ pixels $)$, but using just four photographs were deemed too few to produce an accurate $3 \mathrm{D}$ model and subsequent volumetric estimation aligned to the ultimate objective of the de Bruyn et al. (2009) method. Mean overall RMS values did not differ significantly from one another for any of the different projects (sets of photographs) tested.

(7) Orientation Time. The three methods of photograph orientation (manual only; coded target only; manual and coded target combined) were each subdivided into computer processing time and the human processing time (Table 1). A Kruskal-Wallis test (Chan and Walmsley 1997) was used, which is a type of one-way analysis of variance that utilises a test statistic $H$, probability $P$ and with degrees of freedom $d . f$. This revealed that there was no significant difference between the computer processing times for each category $(H=2.762, d . f .=2, P=0.096)$, but did indicate significant differences between the human processing times for each category $(H=26 \cdot 351, d . f .=2, P<0 \cdot 000)$. Manual orientation of photographs was the most time consuming. Combining coded targets and the manual method (when coded targets are not entirely successful) is slightly less time consuming than the manual method alone. Successful, fully automated photograph orientation reduces human effort to almost zero. 
TABLE I. Time taken (in seconds) to process photogrammetric projects using the respective methods. $\mathrm{SE}=$ Selati Elephant; KH = Kruger Hippopotamus; KR = Kruger Rhinoceros; MR = Mauricedale Rhinoceros; IA = inanimate. Against IA, ph. = photographs.

\begin{tabular}{|c|c|c|c|c|c|c|c|c|c|c|c|c|c|c|}
\hline \multicolumn{5}{|c|}{ Manual processing } & \multicolumn{5}{|c|}{ Automated processing } & \multicolumn{5}{|c|}{ Manual and automated processing } \\
\hline$\frac{\tilde{\Xi}}{\stackrel{\Xi}{0}}$ & 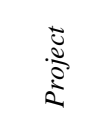 & ن & $\begin{array}{l}\tilde{5} \\
\vdots \\
0 \\
2\end{array}$ & 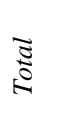 & $\frac{\tilde{u}}{0}$ & $\frac{\tilde{\Xi}}{\stackrel{\Xi}{\Xi}}$ & 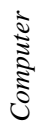 & $\begin{array}{l}\tilde{5} \\
\vdots \\
\vdots \\
2\end{array}$ & $\bar{\Xi}$ & 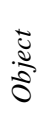 & 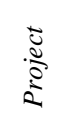 & 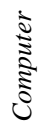 & $\begin{array}{l}\tilde{\delta} \\
\vdots \\
\vdots \\
2\end{array}$ & $\underset{\mathbb{J}}{\mathbb{\Xi}}$ \\
\hline \multirow{5}{*}{ 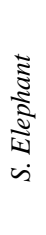 } & SE 8 & 0 & 3060 & 3060 & \multirow{13}{*}{ 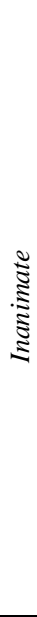 } & IA 4 diag. & 8 & 0 & 8 & \multirow{5}{*}{ 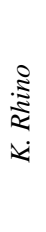 } & KR 1 & 8 & 2700 & 2708 \\
\hline & SE 9 & 0 & 3960 & 3960 & & IA 4 perp. & 8 & 0 & 8 & & KR 3 & 8 & 2460 & 2468 \\
\hline & SE 10 & 0 & 3120 & 3120 & & IA $6 \mathrm{ph}$. & 10 & 0 & 10 & & KR 4 & 9 & 3540 & 3549 \\
\hline & SE 13 & 0 & 3000 & 3000 & & IA $8 \mathrm{ph}$. & 12 & 0 & 12 & & KR 5 & 9 & 3180 & 3189 \\
\hline & SE 14 & 0 & 3480 & 3480 & & IA $10 \mathrm{ph}$. & 13 & 0 & 13 & & KR 6 & 8 & 3960 & 3968 \\
\hline \multirow{11}{*}{ 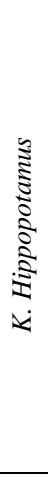 } & KH 2 & 0 & 4020 & 4020 & & IA $12 \mathrm{ph}$. & 15 & 0 & 15 & 8 & MR 3 & 27 & 2160 & 2187 \\
\hline & KH 3 & 0 & 2040 & 2040 & & IA 14 ph. & 17 & 0 & 17 & 站 & MR 5 & 15 & 2880 & 2895 \\
\hline & KH 4 & 0 & 4440 & 4440 & & IA $16 \mathrm{ph}$. & 18 & 0 & 18 & $\Sigma$ & MR 7 & 16 & 3060 & 3076 \\
\hline & KH 5 & 0 & 1800 & 1800 & & IA $18 \mathrm{ph}$. & 26 & 0 & 26 & & & & & \\
\hline & KH 6 & 0 & 3240 & 3240 & & IA $24 \mathrm{ph}$. & 27 & 0 & 27 & & & & & \\
\hline & KH 8 & 0 & 1440 & 1440 & & IA A & 16 & 0 & 16 & & & & & \\
\hline & KH 9 & 0 & 1620 & 1620 & & IA B & 12 & 0 & 12 & & & & & \\
\hline & KH 10 & 0 & 1920 & 1920 & & IA C & 15 & 0 & 15 & & & & & \\
\hline & KH 11 & 0 & 2340 & 2340 & \multirow{3}{*}{ 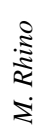 } & MR 9 & 7 & 0 & 7 & & & & & \\
\hline & KH 12 & 0 & 2520 & 2520 & & MR 10 & 10 & 0 & 10 & & & & & \\
\hline & & & & & & MR11 & 13 & 0 & 13 & & & & & \\
\hline
\end{tabular}

\section{DISCUSSION}

When aiming to ease the analytical facets of any given method, both successful and unsuccessful attempts provide a valuable means to a workable end. The unsuccessful projects provided beneficial information with which to adjust the analytical procedure. The inanimate-object trials conducted were all successful and made it possible to test the adjusted analytical procedure comprehensively. From this it was clear that the incorporation of the automated coded targets into the de Bruyn et al. (2009) field method does indeed greatly ease the analytical procedure.

Several elements of the method were tested, with the ultimate goal being to simplify the photograph orientation process as much as possible. Light was a limiting factor for smaller coded targets but not so for the large targets. Targets with a reflective surface were occasionally obscured by glare, but this can be easily avoided in most instances by slightly adjusting the angle at which that particular photograph was taken.

Targets should be as large as possible. The larger the coded targets, the more readily they are identified by the software. The larger the object, the greater the number of coded targets required to effectively surround the object. 
Mounting targets onto various objects proved to be less effective overall than the simple A4 flat sheets with a large, single target. The curved surfaces of the tennis ball and the cone distorted the targets and rendered them unidentifiable by the software. The tennis ball, cone and cube were all too small to accommodate the $25 \mathrm{~mm}$ targets and were not practical to handle in the field. The flat sheets are the most effective as they were better identified by the software, are visible from all camera stations around the object (unlike the other shapes), not constrained by size and the most user-friendly in the field. Although successful, the use of these sheets in the photographic trials was constrained by several factors. The laminated surface of the sheets (for rigidity and waterproofing) tended to be highly reflective which meant that glare affected the results. Although sturdy, the sheets did tend to warp with continued use and this curvature of the targets eventually rendered them unusable. They were easily moved by wind, resulting in a failure of orientation if the photographs were not taken from all angles simultaneously, and often had to be weighed down with stones which caused slight curvature and obstruction from certain camera stations.

Coded targets should make up a minimum of 2040 pixels of the 34532 pixels that constitute a quadrant of the photograph. The size of coded targets within the context of the photograph will differ, based on their position relative to the object; one should aim to take photographs so that the targets furthest from the observer remain of sufficient size (occupying more than 3000 pixels per target). Ideally, the aim is to cover the area surrounding the object with as many coded targets as possible. Obviously this will depend somewhat on the size of the object in question and practical considerations in the field (Fig. 5).

The ideal number of photographs to be taken for a successful project is twelve. However, it should be noted that all projects, whatever the number of photographs, yielded an overall RMS value that was significantly lower than $5 \cdot 00$ pixels. Due to the greatly reduced processing time, the major limiting factor as far as the number of photographs is concerned is how many photographs can be taken in the field. But ideally the photographer should aim for a minimum of 12 photographs.

The successful orientation of the photographs of a particular project, together with the time taken to do so, is used as an indication of the time-saving efficiency of a particular method. A manual project may take several hours to orientate all available photographs; a manual project including coded targets takes slightly less time; but the time required to automatically orientate photographs containing coded targets is reduced to a matter of seconds. Figs. 4 and 5 illustrate a successful photogrammetric project of an immobilised rhinoceros utilising coded targets. 
BESTER AND DE BRUYN. Photogrammetric analysis of large mammal mass: automated targeting and 3D models

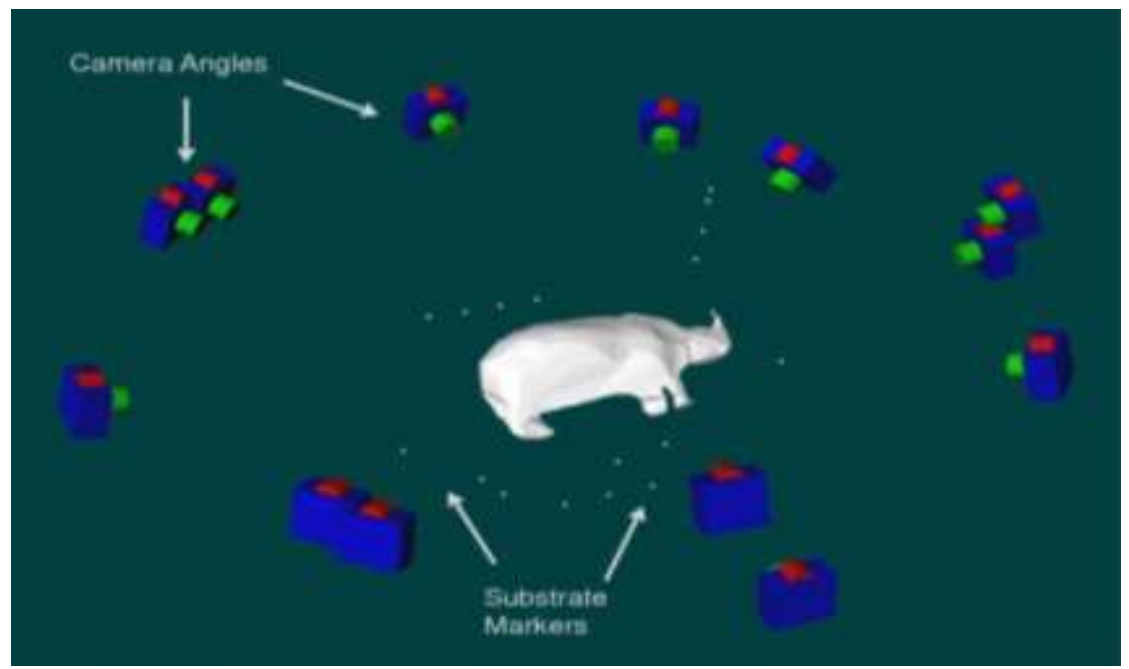

FIG 4. 3D model of immobilised rhinoceros, indicating the coded targets (substrate markers) and camera stations and angles.
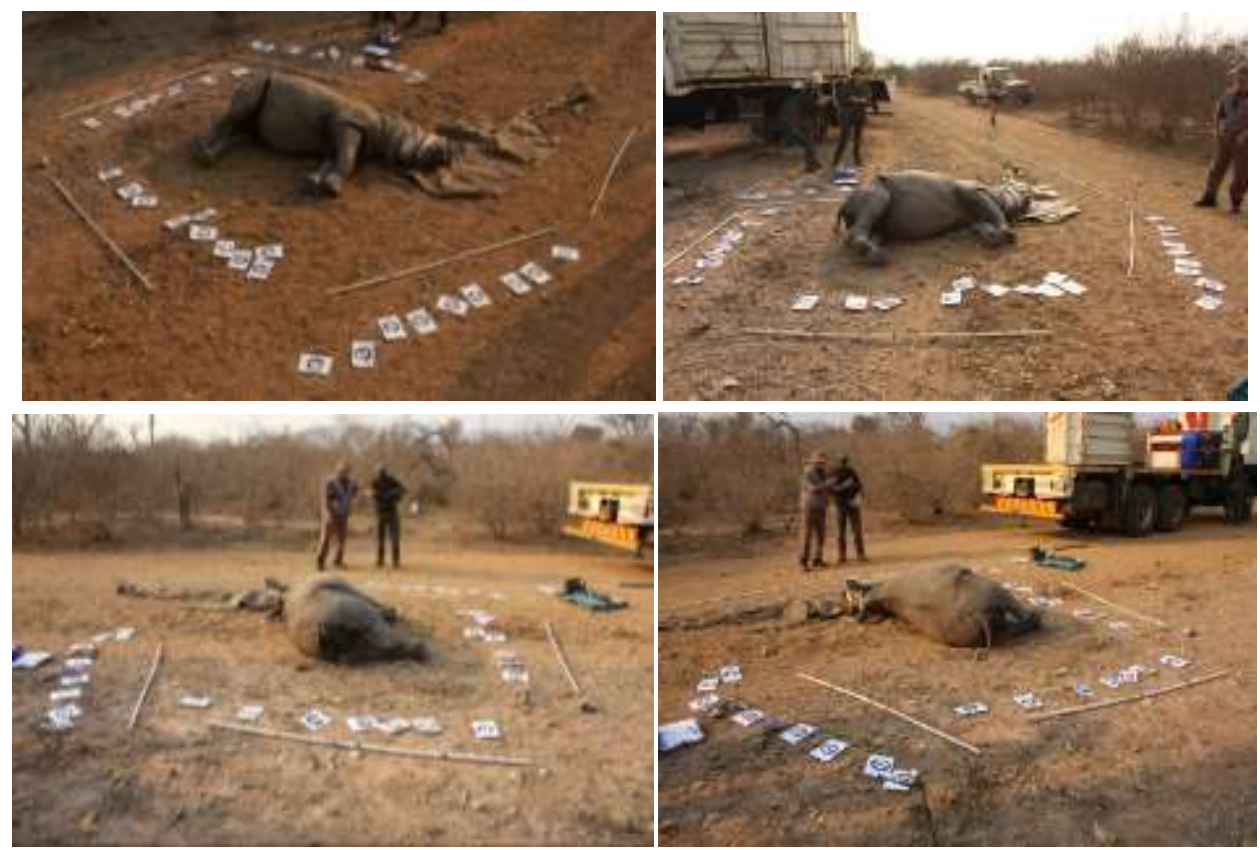

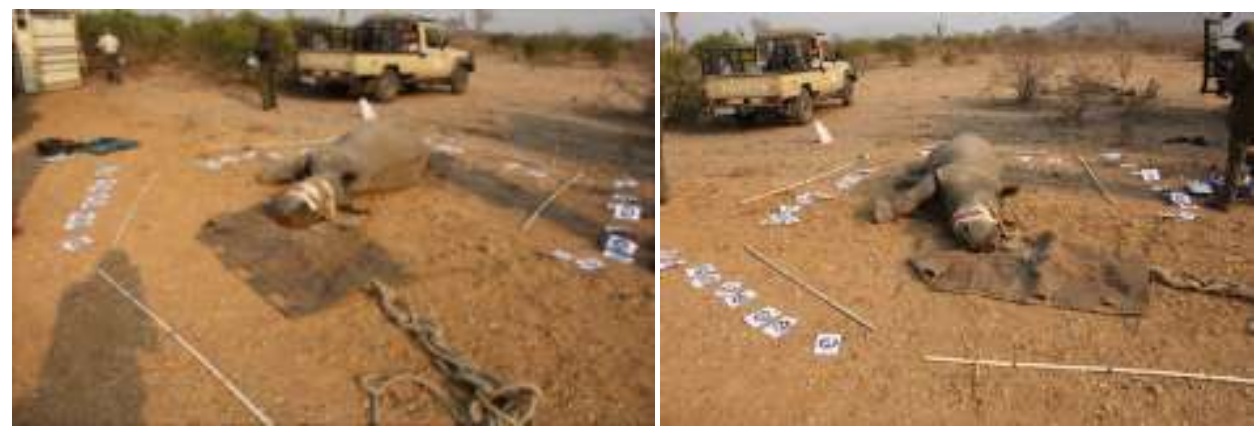

FIG. 5. Six photographs, from various angles, of an immobilised rhinoceros surrounded by coded targets and measuring implements using the de Bruyn et al. (2009) field setup. See also Fig. 4.

Several advances have been made in the simplification of various aspects of closerange photogrammetry over recent decades (Almagro, 1993; Kowalczyk et al. 2008). This contribution to method simplification is yet another step towards simple, efficient, and time-saving photogrammetric methodology. Clearly, supplementing the existing manual method with coded targets in the manner outlined greatly streamlines the analytical part of this photogrammetric method, further increasing its applicability in the zoological field.

\section{FIELD RECOMMENDATIONS}

The following practical recommendations are made as a result of this research.

(1) The targets should be printed out (in black-on-white) and attached to a rigid surface, for example onto aluminium plates, to eliminate any warping of the sheets, to make them more durable, and to provide sufficient weight to withstand windy conditions,

(2) The surface should be a matte finish, rather than reflective or glossy, to reduce any reflections off the target surfaces.

(3) These target plates should be strung together using a non-tangling cord, possibly parachute cord, to ease placement and collection in the field.

(4) Large targets $(25 \mathrm{~mm})$ should be laid out around the object in question, covering as much of the surrounding area that will be visible within the photograph frame as possible.

(5) At least twelve photographs of the object are recommended, taken from various positions and angles, as indicated by de Bruyn et al. (2009).

(6) To ensure successful photograph orientation by the software, at least $25 \%$ of each photograph should be occupied with the coded targets.

\section{CONCLUSIONS}

This study further has contributed to the applicability of the de Bruyn et al. (2009) photogrammetric method, by considerably alleviating the daunting analytical timeframe of the original method. It has been demonstrated that, with the addition of coded targets to projects, analysis time can be reduced by over $90 \%$, even if the automated process is 
BESTER AND DE BRUYN. Photogrammetric analysis of large mammal mass: automated targeting and 3D models

incapable of completely solving the orientation of photographs in a given project.

\section{ACKNOWLEDGEMENTS}

We thank Mr. Martin Postma for valuable technical assistance. Mr. James Hargrave and Mr. Mark Savoy at EOS Systems Inc. provided technical Photomodeler related information. Dr. Peter Buss and Dr. Markus Hofmeyr of Veterinary Wildlife Services at the Kruger National Park and Dr. Kobus Raath and the staff of Mauricedale Game Ranch facilitated some of our fieldwork. University of Pretoria provided financial support for this research through its Research Development Program.

\section{REFERENCES}

Almagro, A., 1993. Simplified methods in architectural photogrammetry, 14th International Symposium of Architectural Photogrammetry Delphi, Greece, 2-5 October 1991. Pages 209-225.

AHN, S. J., RAUH, W. and KIM, S. I., 2001. EstimatCircular coded target for automation of optical 3Dmeasurement and camera calibration. International Journal of Pattern Recognition and Artificial Intelligence, 15(6): 905-919.

Bell, C. M., Hindell, M. A. and Burton, H. R., 1997. Estimation of body mass in the southern elephant seal, Mirounga leonina, by photogrammetry and morphometrics. Marine Mammal Science, 19(4): 669-682.

BERGER, J., 2012. Estimation of body-size traits by photogrammetry in large mammals to inform conservation. Conservation Biology, 26(5): 769-777.

Bergeron, P., 2007. Parallel lasers for remote measurements of morphological traits. The Journal of Wildlife Management, 71(1): 289-292.

Chan, Y. and WALmSLeY, R. P., 1997. Learning and understanding the Kruskal-Wallis one-way analysis-ofvariance-by-ranks test for differences among three or more independent groups. Physio Therapy, 77: 17551761.

Darveau, C. A., Suarez, R. K., Andrews, R. D. and Hochachda, P. W., 2002. Allometric cascade as a unifying principle of body mass effects on metabolism. Nature, 417: 166-170.

De Bruyn, P. J. N., Bester, M. N., CArlini, A. R. and Oosthuizen, W. C., 2009. How to weigh an elephant seal with one finger: a simple three-dimensional photogrammetric application. Aquatic Biology, 5: 31-39.

FRASER, C. S., 1997. Innovations in automation for vision metrology systems. Photogrammetric Record, 15(90): 901-911.

FuSSELL, A., 1982. Terrestrial photogrammetry in archaeology. World Archaeology, 14(2): 157-172.

GANCI, G. and HANDLEY, H., 1988. Automation in videogrammetry. International Archives of Photogrammetry and Remote Sensing, 32(5): 53-58.

Haley, M. P., Deutsch, C. J. and Le Boeuf, B. J., 1991. A method for estimating mass of large pinnipeds. Marine Mammal Science, 7(2): 157-164.

Hattori, S., Aкimoto, K., Fraser, C. and Imoto, H., 2002. pplicAutomated procedures with coded targets in industrial vision metrology. Photogrammetric Engineering \& Remote Sensing, 68(5):441-446.

Ireland, D., GarrotT, A. and Rotella, J., 2006. Development and application of a mass-estimation method for Weddell seals. Marine Mammal Science, 22(2): 361-378.

KowAlCZYK, M., KoZA, P., KuPIDURA, P. and MARCINIAK, J., 2008. Application of mathematical morphology operations for simplification and improvement of correlation of images in close-range photogrammetry. International Archives of the Photogrammetry, Remote Sensing and Spatial Information Sciences, 37(B5): 153-157.

LuHMANN, T., 2010. Close range photogrammetry for industrial applications. ISPRS Journal of Photogrammetry and Remote Sensing, 65: 558-569. 
Pappa, R. S., Black, J. T., Blandino, J. R., Jones, T. W., Danchy, P. M. and Dorrington, A. A., 2003. Dotprojection photogrammetry and videogrammetry of gossamer space structures. Journal of Spacecraft and Rockets, 40(6): 858-867.

Proffitt, D. M., Garrott, R. A. and Rotella, R. A., 2008. Using form analysis techniques to improve photogrammetric mass-estimation methods. Marine Mammal Science, 24(1): 147-158.

RATNASWAMY, M. J. and WinN, H. E., 1993. Photogrammetric estimates of allometry and calf production in fin whales, Balaenoptera physalus. Journal of Mammalogy, 74(2): 323-330.

REMONDINO, F. and FrASER, C., 2006. Digital camera calibration methods: considerations and comparisons. International Archives of Photogrammetry, Remote Sensing and Spatial Information Sciences, 36(5): 266272 .

Rothman. J. M., Chapman, C. A., Twinomugisha, D., Wasserman, M. D., Lambert, J. E. and GoldBerg, T. L., 2008. Measuring physical traits of primates remotely: the use of parallel lasers. American Journal of Primatology, 70(12): 1191-1195.

SCHNEIDER, C. T. and SinNREICH, K., 1992. Optical 3-D measurement systems for quality control in industry. International Archives of Photogrammetry and Remote Sensing, 29(B5): 56-59.

SHORTIS, M. R. and SEAGER, J. W., 2014. A practical target recognition system for close range photogrammetry. Photogrammetric Record, 29(147): 337-355.

SwiHART, R. K., Slade, N. A. and BergStrom, B. J., 1988. Relating body size to the rate of home range use in mammals. Ecology, 69(2): 393-399.

VAN DEN Heuvel, F. A., Kroon, R. J. G. A. and Le Poole, R. S., 1992. Digital close-range photogrammetry using artificial targets. International Archives of Photogrammetry and Remote Sensing, 29(B5): 222-229.

van den Hoff, J., Fraccaro, R., Mitchell, P., Field, I., McMahon, C., Burton, N. H., Blanchard, W., DUIGNAN, P. and Rogers, T., 2005. Estimating body mass and condition of Leopard seals by allometrics. Journal of Wildlife Management, 69(3): 1015-1023.

Waite, J. N., Schrader, W. J., Mellish, J. E. and Horning, M., 2007. Three-dimensional photogrammetry as a tool for estimating morphometrics and body mass of Stellar sea lions (Eumetopias jubatus). Canadian Journal of Fisheries and Aquatic Sciences, 69(2): 296-303.

WESTERn, D., 1979. Size, life history and ecology in mammals. African Journal of Ecology, 17(4): 185-204.

\section{Résumé}

La photogrammétrie rapprochée a des applications pratiques de plus en plus variées dans le domaine des sciences biologiques. Son utilisation s'est avérée précieuse dans la recherche sur les grands mammifères, pour l'estimation de leur taille et/ou de leur masse. Les récents progrès de la photogrammétrie ont permis des applications dans ce domaine, bien que certaines fonctionnalités demeurent chronophages. L'utilisation de cibles codées avec des logiciels du commerce a été évaluée pour simplifier l'analyse photogrammétrique sans en compromettre la faisabilité pratique. Les influences de la taille et de la forme variables des cibles, des conditions d'éclairement, du nombre de clichés, de recouvrement des cibles par les photographies et du temps de traitement, sont étudiées. Le fait d'enrichir une technique photogrammétrique préalablement publiée en incluant des cibles codées permet une réduction significative du temps d'analyse. Cette méthode simplifiée présente un attrait certain pour une vaste communauté d'utilisateurs, experts ou non, pour des applications au domaine de la photogrammétrie animale.

\section{Zusammenfassung}

Die Nahbereichsphotogrammetrie fasst in verschiedenen praktischen Anwendungen in der Biologie zunehmend Fuß. Ihr Einsatz zur Erforschung großer Säugetiere für Größen- und/oder Masseschätzungen haben sich als sehr fruchtbar 
BESTER AND DE BRUYN. Photogrammetric analysis of large mammal mass: automated targeting and 3D models

erwiesen. Durch die jüngsten Fortschritte in der photogrammetrischen Erfassung konnte die Anwendbarkeit weiter gesteigert werden, obwohl einige analytische Komponenten zeitaufwändig bleiben. Eine Anwendung automatisch erfasster kodierter Zielmarken, in Verbindung mit kommerzieller Software, wurde überprüft, $o b$ damit die photogrammetrische Analyse vereinfacht werden kann, ohne allerdings ihren praktischen Nutzen einzuschränken. Die Auswirkungen von variablen Zielmarkengrößen und -formen, die Beleuchtungsbedingungen, die Anzahl von Aufnahmen, die Abdeckung mit Zielmarken und die Prozessbearbeitungszeiten wurden analysiert. Es konnte festgestellt werden, dass eine klassische photogrammetrische Erfassung durch die Hilfe von kodierten Zielmarken einen reduzierten Analyseaufwand erlaubt. Die damit vereinfachte Methode kann für einen größeren Anwenderbereich, sei es Spezialist, oder auch Nichtspezialist, für Anwendungen in der photogrammetrischen Aufnahme von Tieren eingesetzt werden. 